\title{
Grease Lubrication of Self-Mated 60NiTi Bearing Materials
}

\author{
Azhar Vellore ${ }^{\dagger}$, Nicholas Walters ${ }^{\dagger}$ and Ashlie Martini ${ }^{\star \dagger}$ \\ Department of Mechanical Engineering, University of California, Merced, Merced, CA, United States
}

60NiTi is an intermetallic alloy of nickel and titanium that exhibits a unique combination of properties, including hardness comparable to steel, almost twice the elasticity of steel, high corrosion resistance, and tensile strength comparable to ceramics. These properties are very desirable for bearing materials, especially those used in space applications where components must operate efficiently and reliably in harsh conditions. However, despite the fact that most bearings are grease lubricated, there has not been a systematic study of the tribo-performance of greases for 60NiTi lubrication. To address this, we compare the wear and friction of self-mated 60NiTi lubricated by different greases, including those currently used in space missions and general-purpose grease, in low speed sliding contacts. The results provide valuable information to guide selection of

OPEN ACCESS

Edited by:

Yan Zhou,

Oak Ridge National Laboratory (DOE),

United States

Reviewed by:

Paul Shiller,

University of Akron, United States

Georgios Mavropoulos,

National Technical University of

Athens, Greece

*Correspondence:

Ashlie Martini

amartini@ucmerced.edu

tThese authors have contributed equally to this work

Specialty section:

This article was submitted to Engine and Automotive Engineering, a section of the journal Frontiers in Mechanical Engineering

Received: 06 December 2018 Accepted: 19 March 2019 Published: 18 April 2019

Citation:

Vellore A, Walters $N$ and Martini A (2019) Grease Lubrication of Self-Mated 60NiTi Bearing Materials.

Front. Mech. Eng. 5:13.

doi: 10.3389/fmech.2019.00013 grease for 60NiTi contacts as well as lay the groundwork for possible development of new greases specifically for $60 \mathrm{NiTi}$ tribo-contacts.

Keywords: non-ferrous alloys, nickel-titanium alloy, 60NiTi, grease lubrication, space tribology, bearings, wear testing

\section{INTRODUCTION}

Bearings materials are predominantly hardened steel, austenitic stainless steel, and ceramics, as well as sometimes non-ferrous alloys and plastics. These materials have both advantages and disadvantages for a given application. For example, hardened steels are cheap but suffer from weak corrosion resistance; austenitic steels are corrosion resistant but not very hard; ceramics are very light and hard but extremely brittle; and non-ferrous alloys are cheap to produce but cannot withstand high pressures and temperatures. However, some bearing applications require materials with different combinations of these properties. One material being considered for this purpose is $60 \mathrm{NiTi}$, a Nickel-Titanium alloy that consists of $60 \mathrm{wt} . \% \mathrm{Ni}$ and $40 \mathrm{wt} . \% \mathrm{Ti}$. $60 \mathrm{NiTi}$ is nonmagnetic and has high hardness (can be hardened to $62 \mathrm{HRC}$ ) with elasticity twice that of steel, excellent corrosion resistance, tensile strength comparable to ceramics, and is $15 \%$ lighter than steel (Ingole, 2013). This combination of properties makes $60 \mathrm{NiTi}$ a potential alternative bearing material (DellaCorte et al., 2009, 2012). One application where 60NiTi is being considered for bearings is moving components in space vehicles, where the materials have to exhibit high hardness, moderate elastic modulus, and large recoverable strain to enable components to resist impact loads that occur during launch (DellaCorte et al., 2012).

Most potential applications for $60 \mathrm{NiTi}$ include tribo-contacts lubricated by oil or grease. Thus, there is a need to understand the lubrication performance of $60 \mathrm{NiTi}$ in rolling and sliding contacts, which are the primary contact modes in bearings and gear applications. Some studies have been performed using unformulated oils, to minimize the number of variables and to enable isolation of lubrication mechanisms. Unformulated lubricant friction and wear tests have been performed using castor oil, seed oil, turbine oil, and paraffin oil (Zeng and Dong, 2014) where castor oil was found to exhibit lower friction and wear compared to the other oils. Similar studies showed that, at low 
contact pressures, a $60 \mathrm{NiTi}$ pin and 52100 steel sliding contact lubricated by castor oil can exhibit ultra-low friction (friction coefficient of 0.008) (Zeng and Dong, 2013, 2014; Zeng et al., 2016). This result was later found to be strongly dependent on surface roughness, with the lowest friction only achievable with an average surface roughness of $<20 \mathrm{~nm}$ (Walters and Martini, 2018). Experiments using a 60NiTi pin sliding on 52100 steel were carried out with poly-alpha-olefin (PAO) oil and showed that the lubricant decreased the friction coefficient from 0.6 to 0.1 (relative to dry sliding) and improved wear resistance (Zeng et al., 2012). Tests with a linear reciprocating tungsten carbide ball on a $60 \mathrm{NiTi}$ plate using castor oil lubrication identified plastic deformation-induced abrasion as the primary wear mode (Khanlari et al., 2018a). In another study, it was found that friction and wear resistance of $60 \mathrm{NiTi}$ is worse than that of $440 \mathrm{C}$ stainless steel under castor oil lubrication with a sliding tungsten carbide ball (Khanlari et al., 2018b); in a follow-up study, the authors suggested this was due to 60NiTi exhibiting microscopic brittleness at the contact which allowed propagation of tensile microcracks leading to more wear (Khanlari et al., 2018c).

Studies with fully formulated oils have also been performed. A spiral orbit tribometer was used to characterize multiplyalkylated cyclopentane (MAC) oil (DellaCorte et al., 2009, 2012; Pepper et al., 2009, 2010; DellaCorte, 2010) and perfluorinated polyether (PFPE) oils (Pepper et al., 2009, 2010). The MAC oil (commercial name Pennzane 2001A) and PFPE oils (Krytox $143 \mathrm{AC}$ and Castrol Brayco 815Z) are commonly used in space applications. These studies showed that fully-formulated oils can successfully lubricate 60NiTi on 440C (Pepper et al., 2009) and self-mated 60NiTi rolling-sliding contacts (Pepper et al., 2010). It was also found that $60 \mathrm{NiTi}$ is amenable to conventional oil lubrication with a low constant coefficient of friction $(\mathrm{CoF})$ and that this contact exhibits lubricant degradation rates similar to iron-based materials (440C and 52100 steels) (Pepper et al., 2010). Further, linear reciprocating wear testing was used to study synthetic gear oil in sliding contacts (Khanlari et al., 2018a,b). These studies showed that a tungsten carbide ball sliding on a $60 \mathrm{NiTi}$ flat exhibited higher wear and friction than on a $440 \mathrm{C}$ flat, although the reasons for this difference are still not fully understood (Khanlari et al., 2018a).

To date there have been few studies of $60 \mathrm{NiTi}$ sliding against a similarly hard material (either a hardened steel or self-mated) with fully formulated oils or greases. Also, to the best of our knowledge, there have been no grease lubricated sliding contact studies using self-mated $60 \mathrm{NiTi}$. Such studies are necessary to understand how this material will behave in gears and bearings lubricated by greases containing additives not specifically designed for $60 \mathrm{NiTi}$. In this paper, we characterize the friction and wear of self-mated $60 \mathrm{NiTi}$ contact in pure sliding at low speeds, conditions chosen to capture material wear behavior under extreme conditions, i.e., when the contact is lubricant-starved and ceases rolling. Tests are performed with greases consisting of different base oil types and thickener types to enable direct comparison between the greases. Results are then analyzed to explore the friction and wear mechanisms exhibited by grease-lubricated, self-mated $60 \mathrm{NiTi}$ in sliding contacts.

\section{METHODOLOGY}

\section{Materials}

Five different greases were used in this study, as summarized in Table 1. Three of these (Braycote 601EF, Braycote 602EF, and Nye Rheolube 2000) are currently being used in space/vacuum applications where low outgassing and low volatility are necessary. Nye Rheolube $374 \mathrm{~A}$ is used in the aviation industry and SKF LGMT2 is a general-purpose grease used in automotive bearings, conveyor belts, small electric motors, etc. This combination of greases was selected to provide performance data for self-mated $60 \mathrm{NiTi}$ tribo-contacts in space/vacuum applications as well as for terrestrial applications. It should be noted that the base fluids of some greases tested here are the same as those of formulated oils characterized in previous studies of self-mated rolling-sliding contact, i.e., the base oil in Braycote 601EF and Braycote 602EF is Castrol Brayco $815 Z$ and the base oil in Nye Rheolube 2000 is Pennzane 2001A (DellaCorte et al., 2009, 2012; Pepper et al., 2009; DellaCorte, 2010; Pepper et al., 2010).

Ball and flat samples used in this study were $60 \mathrm{NiTi}-\mathrm{Hf}$, an alloy containing one atomic percent Hafnium, and were donated by the NASA Glenn Research Center (subsequently referred to simply as $60 \mathrm{NiTi}$ ). The flat samples were polished in two steps using an Allied High Tech Metprep 3 polisher, first with silicon carbide abrasive pads and second with a polycrystalline diamond abrasive in a hexylene glycol suspension for final surface finish. The average roughnesses of the ball and flat were 46 and $6 \mathrm{~nm}$, respectively, as measured using a white light interferometer. Prior to each test, the surfaces of the ball and flat were thoroughly cleaned with acetone and, if fluorinated oil was present, with Vertrel XF. The flat was also ultrasonically cleaned in heptane for $5 \mathrm{~min}$. Approximately $0.5 \mathrm{~g}$ of grease was evenly spread along the ball path on the flat prior to testing.

\section{Testing}

The tribological performance of the greases was measured using an Rtec Instruments Multi-Function Tribometer. Tests were performed following an adaptation of the ASTM G133-05 standard for linear reciprocating ball-on-flat sliding wear tests, with modifications necessitated by limitations of the available test instrumentation. The ASTM standard recommends lubricated wear testing with a ball of diameter $9.53 \mathrm{~mm}$ at $150^{\circ} \mathrm{C}, 10 \mathrm{~mm}$ stroke length, $10 \mathrm{~Hz}$ oscillating frequency, $400 \mathrm{~m}$ total sliding distance and a constant normal load of $200 \mathrm{~N}$ which corresponds to $1.6 \mathrm{GPa}$ maximum Hertz contact pressure for a self-mated $60 \mathrm{NiTi}$ contact. However, our tests were performed with a $4.76 \mathrm{~mm}$ diameter ball at room temperature, $10 \mathrm{~mm}$ stroke length, $0.25 \mathrm{~Hz}$ oscillating frequency, two sliding distances (short $30 \mathrm{~m}$ and long $100 \mathrm{~m}$ ) and a $11.49 \mathrm{~N}$ constant normal load corresponding to a maximum Hertz contact pressure of $1 \mathrm{GPa}$. The low sliding speed used here suggests that the tests were run in the boundary lubrication regime. For each grease, three tests were run with a $30 \mathrm{~m}$ sliding distance and one test with a $100 \mathrm{~m}$ sliding distance. All tests were performed in atmosphere with a measured relative humidity between 35 and 50\%. 
TABLE 1 | Summary of greases used in this study.

\begin{tabular}{|c|c|c|c|}
\hline Grease & Base fluid & Thickener type & Viscosity (cSt) $40^{\circ} \mathrm{C}, 100^{\circ} \mathrm{C}$ \\
\hline SKF LGMT2 & Mineral Oil & Lithium Soap & 110,11 \\
\hline Braycote 601EF & Perfluorinated polyether, PFPE (Castrol Brayco 815Z) & Polytetrafluoroethylene Particles & 148,45 \\
\hline Braycote 602EF (Contains $\mathrm{MoS}_{2}$ ) & Perfluorinated polyether, PFPE (Castrol Brayco 815Z) & Polytetrafluoroethylene Particles & 140,45 \\
\hline Nye Rheolube 374A & Polyalphaolefin, PAO & Lithium Soap & 121,17 \\
\hline Nye Rheolube 2000 & Multiply-alkylated cyclopentane, MAC (Pennzane 2001A) & Sodium Soap & 110,15 \\
\hline
\end{tabular}
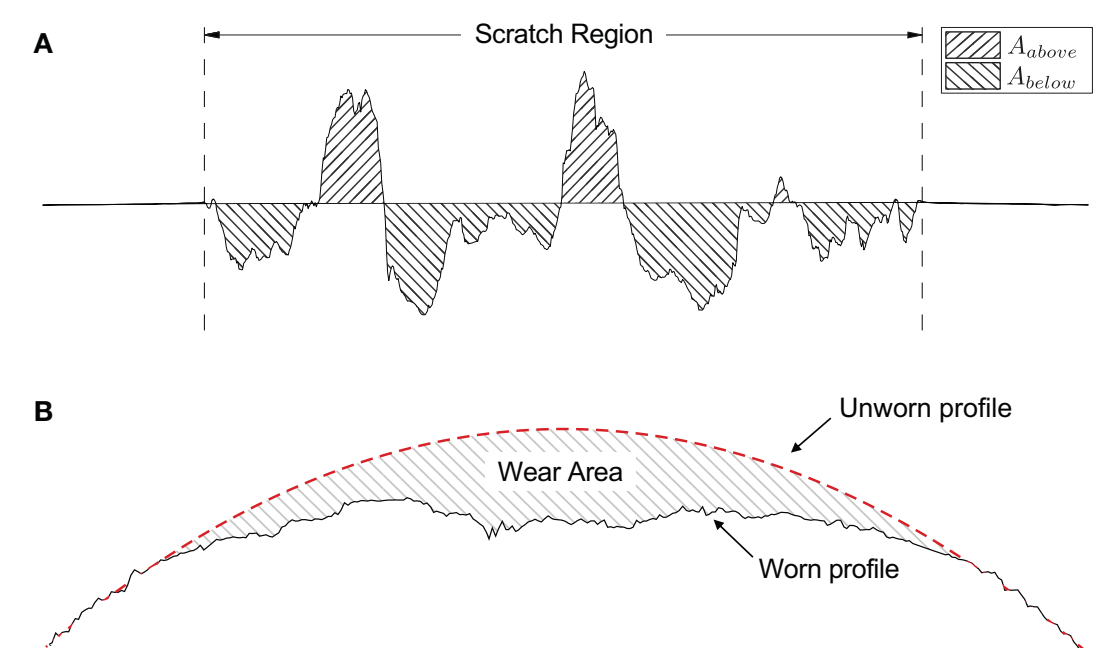

FIGURE 1 | Schematic diagrams illustrating the wear calculations for the flat (A) and the ball (B) samples.

Images of the worn surfaces were obtained from a white light interferometer onboard the tribometer (with data processed using Gwyddion), a Leica (Model DM 2500M) optical microscope, and a Zeiss Gemini 500 scanning electron microscope (SEM). To measure wear volume, the white light interferometer was used to capture high quality 3D images of wear scars on the balls and flats after the $30 \mathrm{~m}$ sliding tests. Prior to imaging, the surfaces of the ball and flat were thoroughly cleaned with acetone and heptane, as well as Vertrel XF if fluorinated oil was present, as described in the previous section. The volume of the wear scars on the flats was calculated as an average of the cross-sectional area of six profiles along the wear scar multiplied by the length of the scar. The crosssectional area of the wear scar was defined as the difference between the areas above and below the average height of the surface (Kato and Adachi, 2001), as shown in Figure 1A. It should be noted that protruding features will increase the area above the average surface height and decrease the calculated wear volume. For small wear cases, the ball wear volume was calculated from the difference between the volume of an unworn ball and that of a worn ball over the entire scar area, as illustrated in Figure 1B In some cases, the wear on the ball was too severe to calculate with this approach, so a spherical cap approximation was used to estimate wear volume geometrically (Stanford, 2018). Specific wear rates were calculated as the wear volume divided by total sliding distance $(30 \mathrm{~m})$ and normal load $(11.49 \mathrm{~N})$.

\section{RESULTS AND DISCUSSION}

The friction and wear behavior are analyzed for self-mated $60 \mathrm{NiTi}$ sliding contact with each grease. First, the $\mathrm{CoF}$ is shown as a function of sliding distance for four tests (three at $30 \mathrm{~m}$ and one at $100 \mathrm{~m}$ ). The friction traces of the three $30 \mathrm{~m}$ tests are shown as red, black and blue, and the $100 \mathrm{~m}$ tests are shown in magenta. Then, representative wear scars on the ball and the flat are shown from one of the $30 \mathrm{~m}$ sliding distance tests for each grease. Wear analyses include interferometer images of the ball wear scar, interferometer, and optical microscope images of flat wear scar, and in some cases, SEM images of the region within the wear scar on the flat.

Test results for the SKF LGMT2 are shown in Figure 2. The $\mathrm{CoF}$ in Figure $2 \mathrm{~A}$ is initially high $(\sim 0.45)$ for all four cases. In one of the $30 \mathrm{~m}$ cases, the friction decreases around $20 \mathrm{~m}$ of sliding. This decrease is also exhibited by the $100 \mathrm{~m}$ case, albeit around $40 \mathrm{~m}$ of sliding. Overall, the friction is never observed to be consistently low with this grease ( $\mathrm{CoF}$ in the range of $0.15-0.4$ ). Figure 2B shows the wear scar on the ball with severe scoring marks parallel to the sliding direction, indicating predominantly abrasive wear (Bhushan, 1963). The corresponding scar on the flat shows faint abrasive wear marks and protruding features, as indicated by blue regions in the interferometer image (Figure 2D) and dark regions in the optical microscope image (Figure 2C). The observed protruding features are likely adhered wear debris. Two regions are magnified in the SEM micrographs 


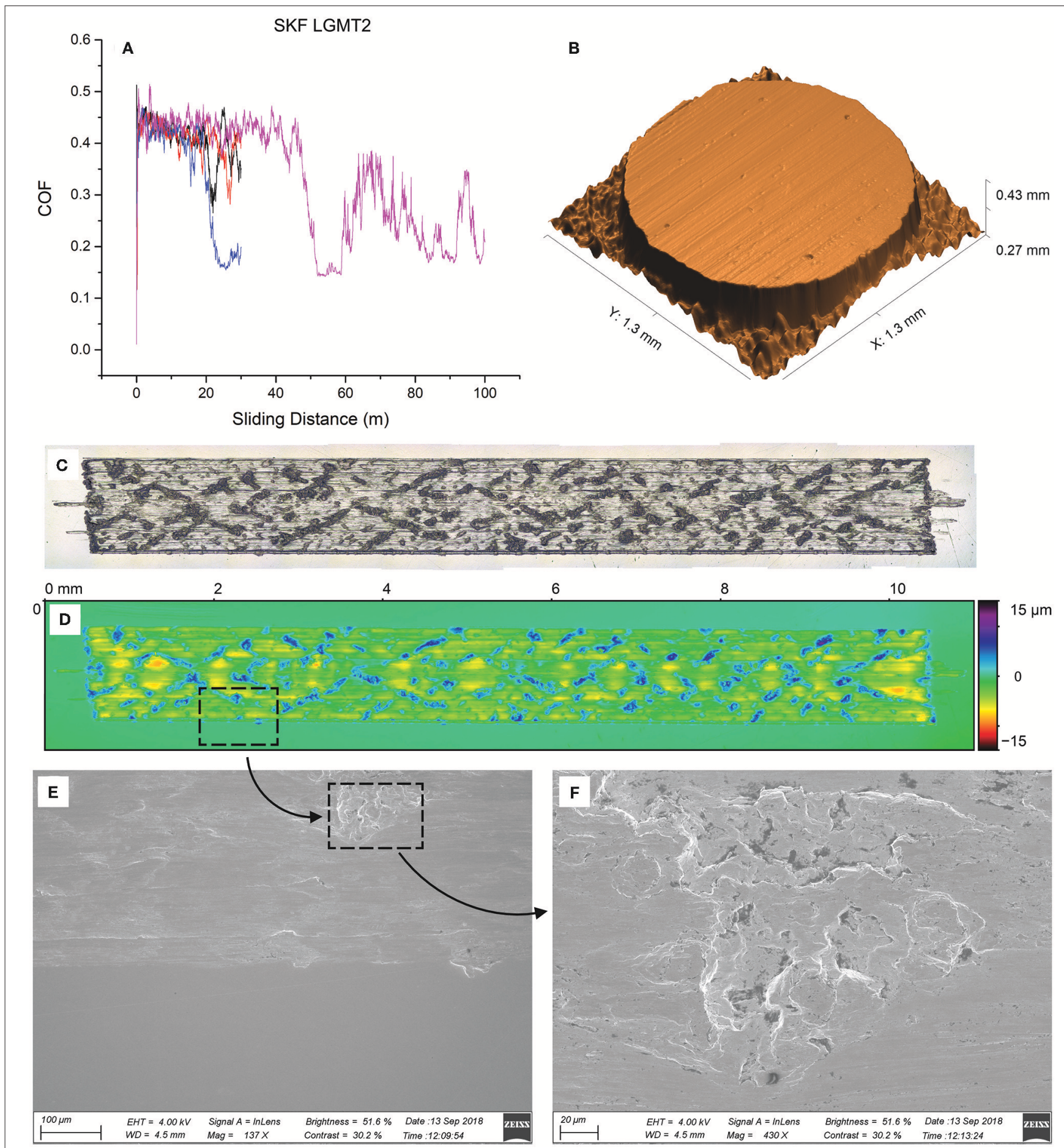

FIGURE 2 | Test results for SKF LGMT2 including (A) friction traces, (B) interferometer image of the ball wear scar, (C,D) optical microscope and interferometer images of the flat wear scar, and (E,F) SEM micrographs of the flat wear scar. All wear images correspond to the test shown in blue in (A).

in Figures 2E,F which show that the size of the adhered features ranges from a few tens to hundreds of microns, indicating this behavior is prevalent across different scales of asperity contact. The large amount of material adhesion is possibly a result of galling (Kato and Adachi, 2001), which would be consistent with the behavior of titanium and its some of its alloys (Roberts and Owens, 1963; Pepper et al., 2009) in sliding. Despite the signs of adhesive wear on the flat, the scoring marks on the ball suggest abrasive wear. To explain this, we postulate that wear debris adheres to the flat, then it is work-hardened due to the severe 


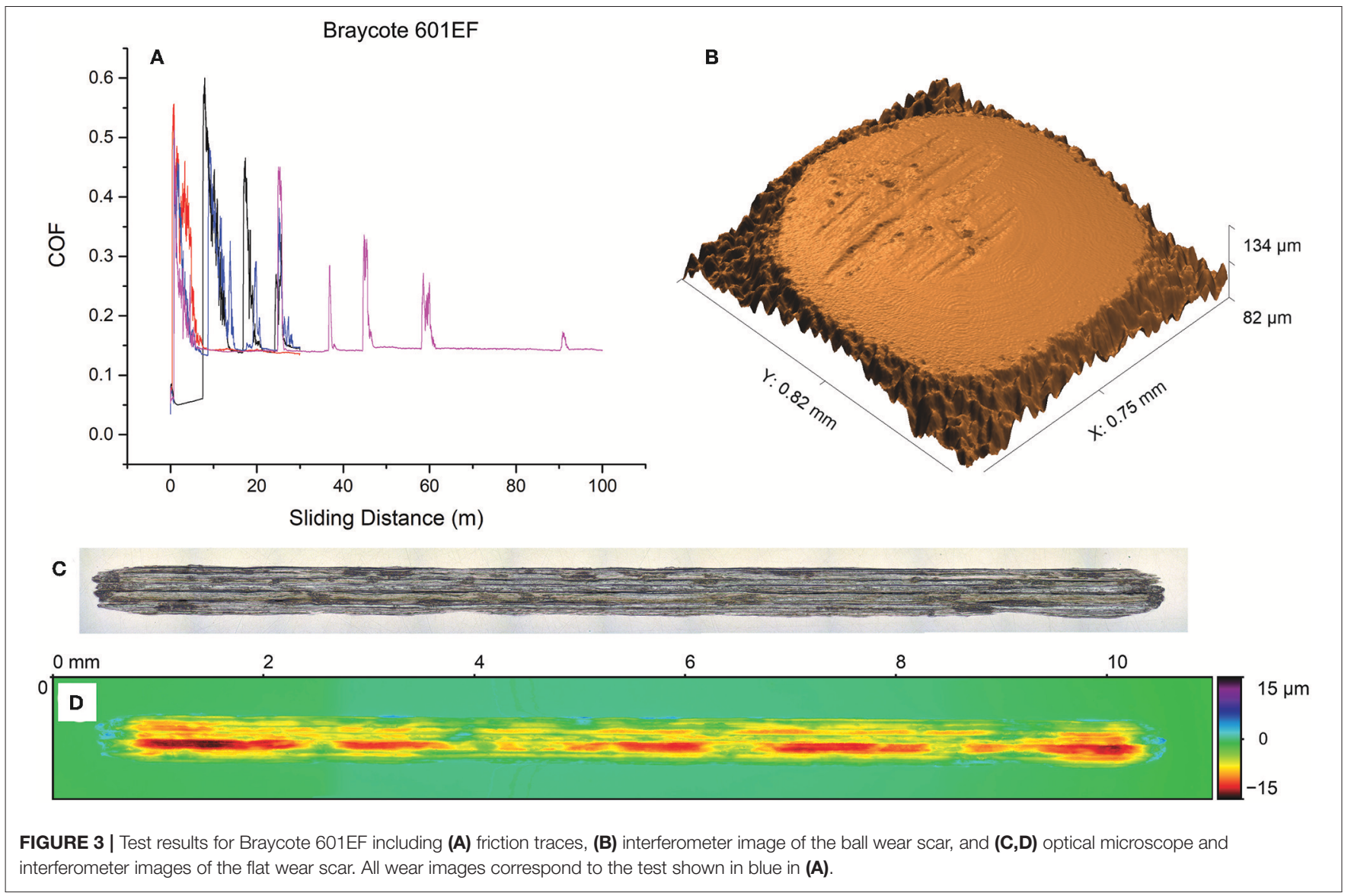

test conditions and finally this hard material on the flat abrades the relatively softer ball.

Test results for Braycote 601EF are shown in Figure 3. The CoF traces in Figure 3A for this grease are consistent across the four tests. In all cases, there is a short run in period followed by low friction (average $\mathrm{CoF}$ of 0.14 after $10 \mathrm{~m}$ of sliding) with intermittent friction peaks, possibly due to wear followed by removal of worn material from the wear track. The longer duration test (100 $\mathrm{m}$ sliding distance) shows that the height and frequency of these friction peaks decrease with sliding distance. Ball wear, shown in Figure 3B, was very low, with a groove in the center of the scar and mild abrasive marks around it. Unlike the SKF LGMT2, there were no protruding features found on the flat wear scar shown in Figures 3C,D, which suggests this contact is dominated by abrasive wear (Bhushan, 1963) as evidenced by the longitudinal grooves in Figure 3D. One outcome of this is that, although the width of the wear scar on the flat is much smaller than that with the SKF LGMT2 shown in Figure 2D, the wear depth is greater (more red and dark red regions) for Braycote $601 \mathrm{EF}$, because there is no adhered material.

Test results for Braycote 602EF are shown in Figure 4. The CoF traces for the $30 \mathrm{~m}$ tests are similar to those from the Braycote $601 \mathrm{EF}$, but with fewer friction peaks. Also, the mean CoF after $10 \mathrm{~m}$ of sliding is slightly lower at 0.13 , possibly due to the presence of $\mathrm{MoS}_{2}$ additive in the grease.
The wear on the ball (Figure 4B) and flat (Figures 4C,D) are also similar to those of Braycote 601EF, characterized by narrow, sometimes deep wear features, indicating abrasive wear. SEM micrographs of the flat wear scar for this grease contain many micron-sized dark spots, as shown in Figures 4E,F. Since the SEM was performed after ultrasonicating the sample in a heptane bath for $5 \mathrm{~min}$ and drying with forced air, it is unlikely these are residual spots of grease. Compositional analysis using energy-dispersive $\mathrm{x}$-ray spectroscopy (EDAX) was performed on these scars to investigate the dark spots, but the results did not conclusively explain their origin. Similar spots were observed with the Braycote 601EF, but were significantly less in superficial density compared to Braycote 602EF.

Test results with Rheolube $374 \mathrm{~A}$ are shown in Figure 5. The CoF traces in Figure 5A exhibit a decrease in friction in the first $7 \mathrm{~m}$ of sliding, after which the friction is erratic and relatively high (average friction of 0.22 as calculated after $15 \mathrm{~m}$ of sliding). This behavior is similar to that of SKF LGMT2, but the friction decreases with sliding distance more quickly with the Rheolube 374A. The longer duration test exhibits the same trends as those run for $30 \mathrm{~m}$, with a rapid friction decrease leading to erratic friction with an average value of 0.22 after $15 \mathrm{~m}$. The interferometer image of the ball wear scar in Figure 5B shows significant wear and abrasive wear marks, 

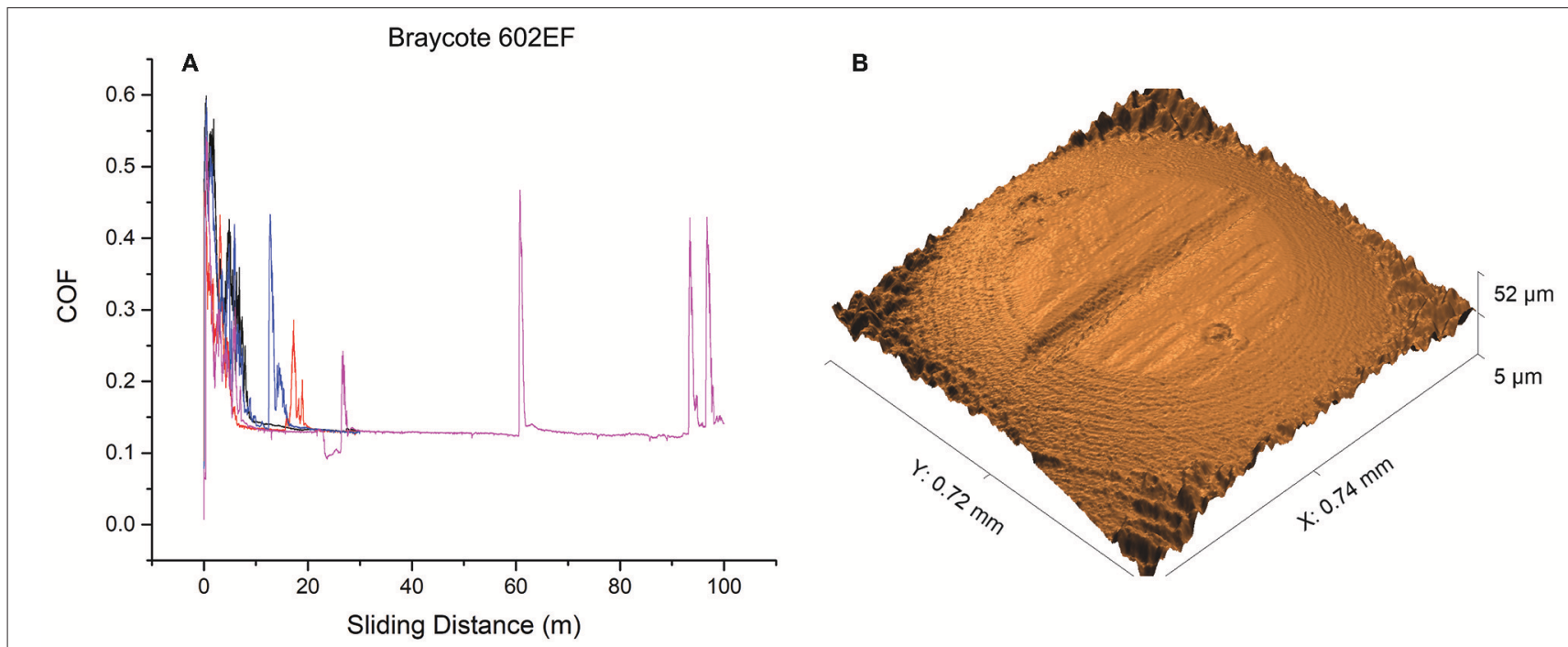

C
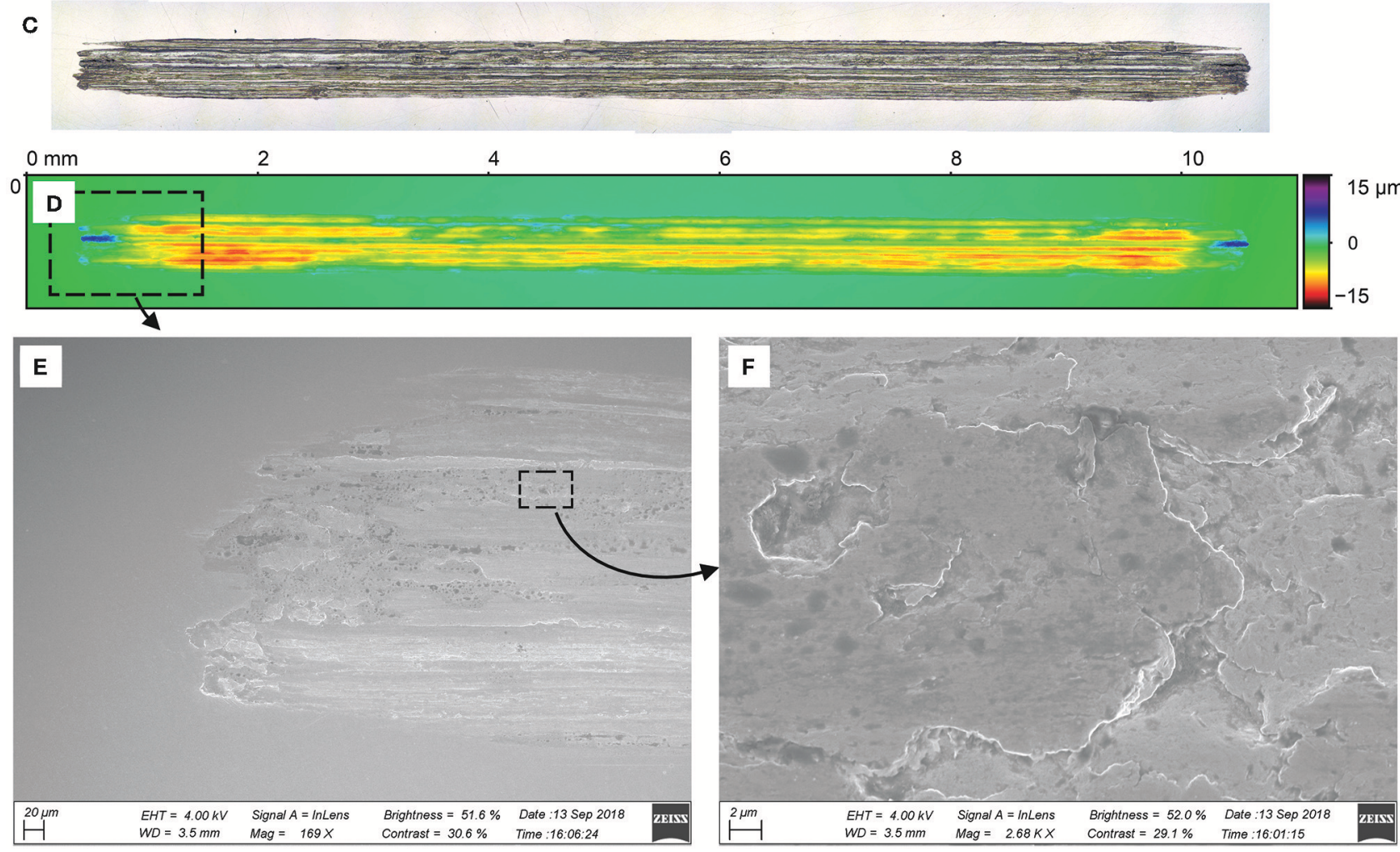

FIGURE 4 | Test results for Braycote 602EF including (A) friction traces, (B) interferometer image of the ball wear scar, (C,D) optical microscope and interferometer images of the flat wear scar, and (E,F) SEM micrographs of the flat wear scar. All wear images correspond to the test shown in blue in (A).

similar to the SKF LGMT2. Also, the wear scars shown in Figures 5C,D suggest a combination of adhesive and abrasive wear, as evidenced by protruding features that are higher than the original surface (blue in the interferometer image) and abrasive scoring marks (yellow streaks). Therefore, the mechanisms of wear may be similar for the SKF LGMT2 and Rheolube 374A. SEM micrographs of the protruding features from the wear scar are shown in Figures 5E,F, and suggest that the material adhered to the flat has been sheared and flattened due to cyclic shear stresses.

Test results with the Rheolube 2000 are shown in Figure 6. This grease exhibits a high CoF (between 0.4 and 0.5 ) until 25 to $30 \mathrm{~m}$ of sliding, after which it drops to a constant value of 0.13 , as shown in Figure 6A. The interferometer image of the ball wear scar in Figure 6B shows severe abrasive wear, similar to that observed with Rheolube 374A and SKF LGMT2. 

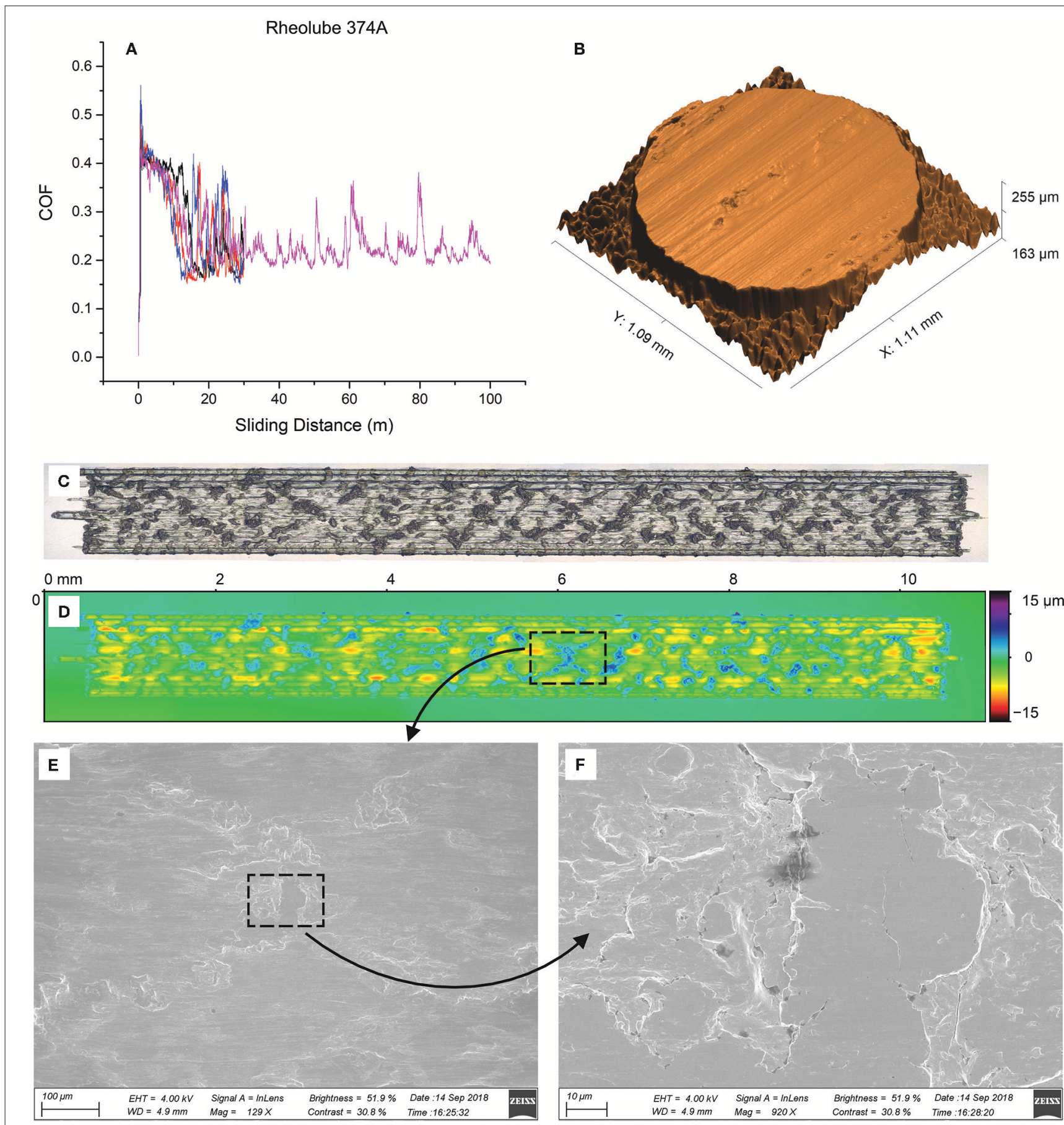

FIGURE 5 | Test results for Rheolube 374A including (A) friction traces, (B) interferometer image of the ball wear scar, (C,D) optical microscope and interferometer images of the flat wear scar, and (E,F) SEM micrographs of the flat wear scar. All wear images correspond to the test shown in red in (A).

The Rheolube 2000 ball wear scar differs, however, in that it exhibits micro-sized pits along with the scoring marks. The flat wear scar width and appearance resemble the Rheolube $374 \mathrm{~A}$ with protruding features and mild abrasive scoring marks. However, unlike the Rheolube 374A and SKF LGMT2, here the presence of adhered material inside flat wear scar and severe abrasion on ball did not result in high, erratic friction in the $100 \mathrm{~m}$ test.

To compare the wear behavior of each grease quantitatively, we calculated the wear volume of the ball and flat from the $3 \mathrm{D}$ interferometer images of the wear scars after all three $30 \mathrm{~m}$ tests. The results are shown in Figure 7. The wear volume comparison 


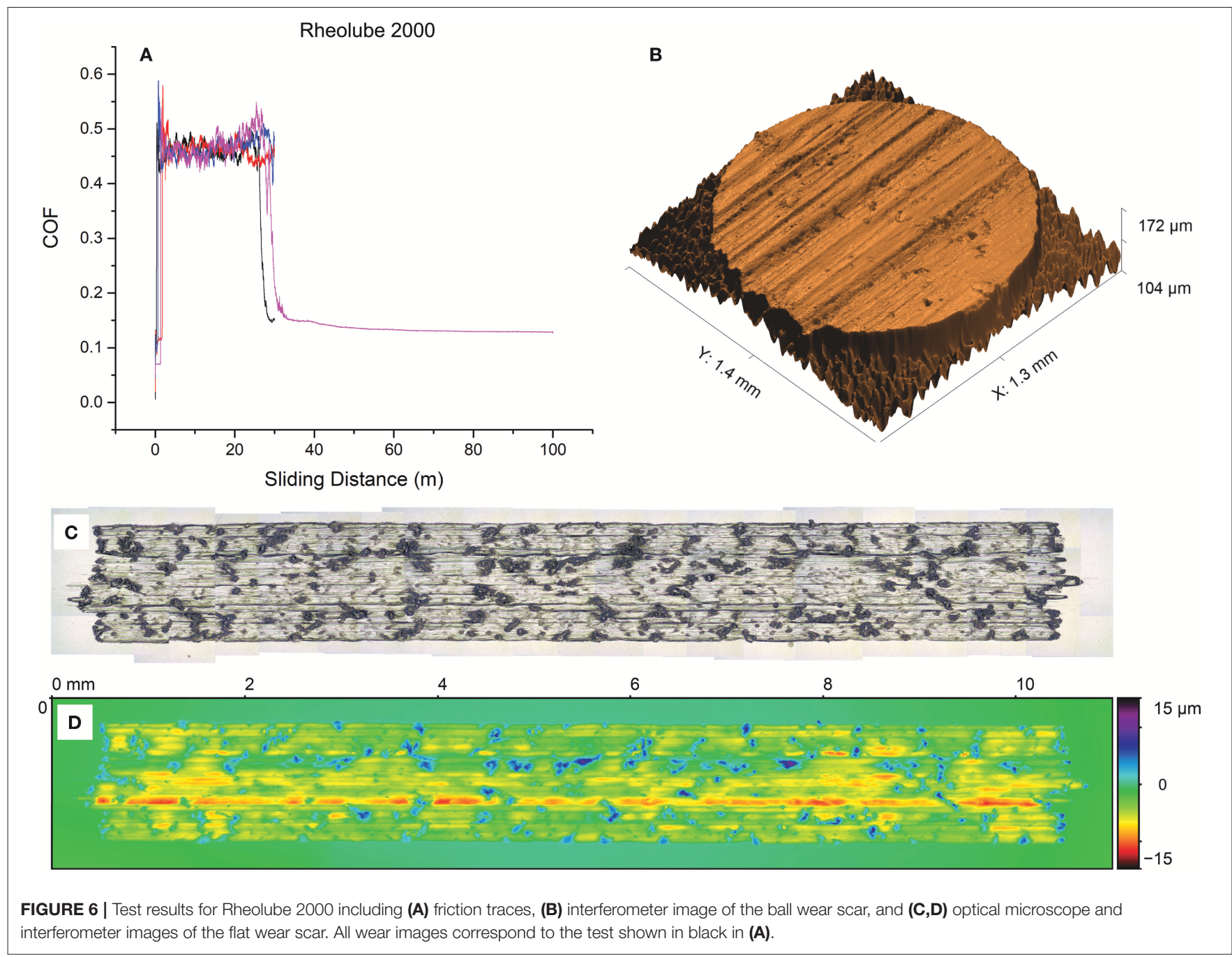

shows that flat wear (Figure 7A) is nearly the same in all cases, except for Rheolube 2000 which has nearly twice the wear of the other greases. However, the similarity in the wear volume is misleading since the SKF LGMT2 and Rheolube 374A wear tracks are wide with significant adhered material, while the flat wear scars of the two Braycote greases are narrower and deeper. The difference in wear performance is more obvious in the comparison of ball wear, shown in Figure 7B. The two Braycote greases have an order of magnitude lower wear than the other greases. This is followed by the Rheolube $374 \mathrm{~A}$, and then the SKF LGMT2 and Rheolube 374A that have the most ball wear. For SKF LGMT2 and Rheolube 374A, the ball wear is greater than that of the flat, likely due to material that adheres to the flat during testing.

The specific wear rates with each grease for the ball, the flat and for both surfaces from the $30 \mathrm{~m}$ tests are summarized in Table 2. The trends in specific wear rate for the ball and flat reflect the trends observed in Figure 7. Also, the flat wear rates in our tests are comparable to those reported in other studies (Khanlari et al., 2018a,b,c) with $60 \mathrm{NiTi}$ sliding against tungsten carbide ball with castor oil or fullyformulated PAO gear oil. The combined wear rates enable direct comparison of the greases and show that, in terms of wear, the greases tested here compare as follows: Nye Rheolube 2000 $<$ SKF LGMT2 < Nye Rheolube 374A < Braycote 602EF $\approx$ Braycote 601EF.

The results from this study can be analyzed in the context of previous reports of $60 \mathrm{NiTi}$ tribo-performance. First, our Rheolube 2000 tests can be compared to spiral orbit tribometer measurements of self-mated 60NiTi using Pennzane 2001A oil lubrication (DellaCorte, 2010), which is the base fluid in Rheolube 2000. Unlike the results shown in Figure 6, the previous study reported that $60 \mathrm{NiTi}$ is amenable to lubrication with Pennzane 2001A and rolling-sliding contact was measured with a low, steady $\mathrm{CoF}$ of $\sim 0.06$ and no material adhesion. The Hertz contact pressure was $\sim 1 \mathrm{GPa}$ in both studies, so the differences are likely due to the severity of the test conditions, i.e., our tests are pure sliding which is much more severe than rolling-sliding contact. Another comparison can be made related to the adhered material features we observed in the flat wear 

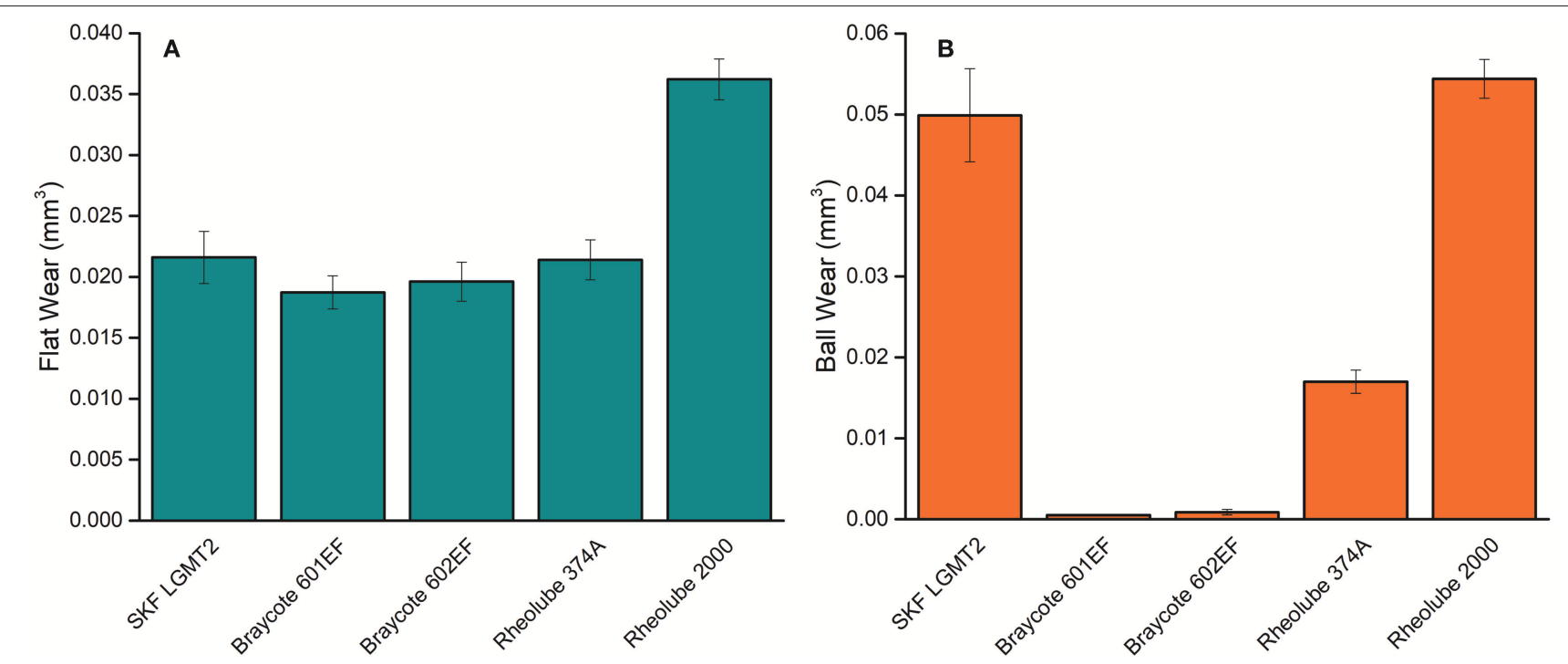

FIGURE 7 | Wear volume averaged over the three $30 \mathrm{~m}$ tests for each grease as measured from the (A) flat and (B) ball. Error bars reflect the standard error of three tests.

TABLE 2 | Specific wear rates $\left(\times 10^{-5} \mathrm{~mm}^{3} / \mathrm{m} \cdot \mathrm{N}\right)$ calculated from the $30 \mathrm{~m}$ tests.

\begin{tabular}{lccc}
\hline Grease & Flat & Ball & Combined \\
\hline SKF LGMT2 & $6.3 \pm 1.1$ & $14.4 \pm 1.7$ & $20.7 \pm 2.0$ \\
Braycote 601EF & $5.4 \pm 0.7$ & $0.2 \pm 0.1$ & $5.6 \pm 0.7$ \\
Braycote 602EF & $5.7 \pm 1.2$ & $0.3 \pm 0.1$ & $5.9 \pm 1.2$ \\
Nye Rheolube 374A & $6.2 \pm 0.7$ & $4.9 \pm 0.4$ & $11.1 \pm 0.8$ \\
Nye Rheolube 2000 & $10.5 \pm 0.9$ & $15.8 \pm 0.7$ & $26.3 \pm 1.1$ \\
\hline
\end{tabular}

tracks for SKF LGMT2, Rheolube 374A and Rheolube 2000. These features are similar to those found in the flat wear tracks after sliding a tungsten carbide ball on $60 \mathrm{NiTi}$ in unlubricated conditions at similar contact pressures (Khanlari et al., 2018b). The composition of the protruding features was measured using energy dispersive $\mathrm{x}$-ray spectroscopy and showed that the material mainly consisted of $\mathrm{Ni}, \mathrm{Ti}, \mathrm{O}$, and a negligibly small amount of ball material, which suggested that the protruding features did not form due to material transfer from ball to flat. In our study of self-mated $60 \mathrm{NiTi}$, it is likely that the protruding features consist of material that was originally from both the ball and the flat. However, no such features were observed in the rolling-sliding spiral orbit tribometer tests for self-mated $60 \mathrm{NiTi}$ lubricated with Pennzane 2001A oil (DellaCorte, 2010). These observations suggest that the protruding features observed in this study may have formed while the ball was sliding against the flat in starved lubrication conditions. It is known that grease lubricated contacts are susceptible to starved lubrication conditions when the grease is unable to supply the contact with a sufficient amount of oil (Poon, 1972; Wilson, 1979; Wikström and Jacobson, 1997; Lugt, 2009), which would explain the similarity between our tests and the unlubricated tests from (Khanlari et al., 2018b).

\section{CONCLUSION}

The goal of this study was to evaluate the tribo-performance of self-mated $60 \mathrm{NiTi}$ under grease lubrication. Five greases were tested, including those currently used in space and terrestrial applications: a mineral-oil-based general-purpose grease (SKF LGMT2), a PFPE-based vacuum grease (Braycote 601EF) and additized with $\mathrm{MoS}_{2}$ (Braycote 602EF), a PAO-based high temperature grease (Rheolube 374A) and a MAC-based vacuum grease (Rheolube 2000). The performance of these greases was evaluated for pure sliding and $1 \mathrm{GPa}$ non-conformal contact, severe conditions that correspond to contacts that are lubricantstarved and cease rolling. We compared the greases in terms of friction force as well as wear measured using an optical microscope, interferometer and SEM imaging of the wear scars on the ball and flat. The observations for each grease are summarized below:

1. SKF LGMT2 exhibited high friction, with a CoF in the range of $0.15-0.4$, even after run-in. The wear on ball was high and almost twice that of the wear on the flat. A significant amount of material adhered to the flat, extending above the original surface height. The wear patterns on the ball and flat suggest that both adhesive and abrasive wear mechanisms are present.

2. Braycote $601 \mathrm{EF}$ and Braycote $602 \mathrm{EF}$ exhibited low CoFs of 0.14 and 0.13 , respectively, with intermittent friction-peaks, likely due to wear followed by wear debris removal from the contact. Fewer and smaller friction peaks were observed with the Braycote 602EF. In both cases, the ball wear was minimal. The flat wear, although narrower than observed with the other three greases, was deeper and did not contain protruding features, reflecting predominantly abrasive wear. The flat wear track with the Braycote 602EF exhibited dark spots, the origin of which was not clear. 
3. With Rheolube 374, the friction decreased quickly (within $17 \mathrm{~m}$ ) to reach an erratic, high friction coefficient between 0.2 and 0.3. Wear on the ball was significantly lower than with the SKF LGMT2, but higher than with the Braycote greases. Wear on the flat suggested a combination of abrasive and adhesive modes.

4. Rheolube 2000 exhibited high friction (CoF between 0.4 and 0.5$)$ until $\sim 30 \mathrm{~m}$, after which it the friction dropped dramatically to an average of 0.13 and remained steady until the end of the long test. Wear was the highest with this grease on both the ball and flat. Protruding features were observed, similar to SKF LGMT2 and Rheolube 374, but in this case their presence did not adversely affect the friction after run-in.

Overall, the PFPE-based vacuum greases (Braycote 601 and 602 $\mathrm{EF}$ ) performed the best, with the lowest friction and wear. Of those two, the 602EF exhibited slightly lower average friction and wear, possibly due to the presence of the $\mathrm{MoS}_{2}$ additive, but the difference was not statistically significant. Comparing the other three greases, the mineral-oil-based general-purpose grease (SKF LGMT2) and MAC-based vacuum grease (Rheolube 2000) performed the worst, exhibiting high friction throughout the test and significant wear. The PAO-based high temperature grease (Rheolube 374A) was moderate in both friction and wear. The results of this study are the first step toward a complete evaluation of the friction and wear performance of

\section{REFERENCES}

Bhushan, B. (1963). "Types of Wear Mechanism," in Introduction to Tribology, eds B. Bhushan, F. E. Kennedy, and A. Z. Szeri 2nd Edn. (Boca Raton, FL: CRC Press), 372.

DellaCorte, C. (2010). Nickel-Titanium Alloys: Corrosion. NASA Tech. Reports Serv.

DellaCorte, C., Noebe, R. D., Stanford, M. K., and Padula, S. A. (2012). "Resilient and corrosion-proof rolling element bearings made from superelastic $\mathrm{Ni}$-Ti alloys for aerospace mechanism applications," in Rolling Element Bearings, ed Y. Takeuchi (West Conshohocken: ASTM International), 143-166.

DellaCorte, C., Pepper, S. V., Noebe, R., Hull, D. R., and Glennon, G. (2009). Intermetallic Nickel-Titanium Alloys for Oil-Lubricated Bearing Applications. NASA Tech. Reports Serv.

Ingole, S. (2013). 60NiTi alloy for tribological and biomedical surface engineering applications. J. Miner Met. Mater. Soc. 65, 792-798. doi: 10.1007/s11837-013-0610-7

Kato, K., and Adachi, K. (2001). "Wear Mechanisms," in Modern Tribology Handbook, Bharat Bhushan, 273-299.

Khanlari, K., Ramezani, M., Kelly, P., Cao, P., and Neitzert, T. (2018a).

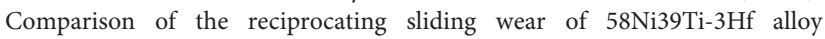
and baseline 60NiTi. Wear. 408-409, 120-130. doi: 10.1016/j.wear.2018. 05.011

Khanlari, K., Ramezani, M., Kelly, P., Cao, P., and Neitzert, T. (2018b). Reciprocating sliding wear behavior of $60 \mathrm{NiTi}$ as compared to $440 \mathrm{C}$ steel under lubricated and unlubricated conditions. Tribol. Trans. 61, 991-1002. doi: 10.1080/10402004.2018.14 60434

Khanlari, K., Ramezani, M., Kelly, P., Cao, P., and Neitzert, T. (2018c). An investigation on reasons causing inferiority in unlubricated sliding wear performance of $60 \mathrm{NiTi}$ as compared to self-mated $60 \mathrm{NiTi}$ contacts. Since the testing was performed under only one set of conditions, the differences between greases cannot be generalized. Future investigations should include rolling-sliding contacts at a range of speeds and other pressure conditions. Further, analysis of the results in the context of a theoretical model could both help explain the observations reported here as well as suggest other tests conditions to be evaluated. A comprehensive set of data for $60 \mathrm{NiTi}$ will facilitate use of this material for more and a wider variety of potential bearing applications.

\section{AUTHOR CONTRIBUTIONS}

All authors listed have made a substantial, direct and intellectual contribution to the work, and approved it for publication.

\section{ACKNOWLEDGMENTS}

This research was supported by the Merced nanomaterials Center for Energy and Sensing (MACES) through the support of the National Aeronautics and Space Administration (NASA) grant no. NNX15AQ01.The authors thank Dr. Christopher DellaCorte for providing 60NiTi-Hf samples as well as guidance throughout the project. The authors would also like to thank Dr. Robert A. Erck for his expert advice and guidance in wear analysis.

440C steel. Tribol. Trans. 62, 1-14. doi: 10.1080/10402004.2018.15 16326

Lugt, P. M. (2009). A review on grease lubrication in rolling bearings. Tribol. Trans. 52, 470-480. doi: 10.1080/104020008026 87940

Pepper, S. V., DellaCorte, C., and Glennon, G. (2010). Lubrication of Nitinol 60. NASA Tech. Reports Serv.

Pepper, S. V., DellaCorte, C., Noebe, R. D., Hall, D. R., and Glennon, G. (2009). Nitinol 60 as a Material For Spacecraft Triboelements. NASA Tech. Reports Serv.

Poon, S. Y. (1972). An experimental study of grease in elastohydrodynamic lubrication. J. Lubr. Technol. 94, 27-34. doi: 10.1115/1.34 51631

Roberts, R. W., and Owens, R. S. (1963). Titanium Lubrication. Nature 200, 357-358. doi: 10.1038/200357a0

Stanford, M. K. (2018). Friction and Wear of Unlubricated NiTiHf With Nitriding Surface Treatments. NASA Tech. Reports Serv.

Walters, N., and Martini, A. (2018). Friction dependence on surface roughness for castor oil lubricated $\mathrm{NiTi}$ alloy sliding on steel. Tribol. Trans. 61, 1162-1166. doi: 10.1080/10402004.2018.15 20949

Wikström, V., and Jacobson, B. (1997). Loss of lubricant from oillubricated near-starved spherical roller bearings. Proc. Inst. Mech. Eng. Part J J. Eng. Tribol. 211, 51-66. doi: 10.1243/13506509715 42318

Wilson, A. R. (1979). The relative thickness of grease and oil films in rolling bearings. Proc. Inst. Mech. Eng. 193, 185-192. doi: 10.1243/PIME_PROC_1979_193_019_02

Zeng, Q., and Dong, G. (2013). Influence of load and sliding speed on super-low friction of nitinol 60 alloy under castor oil lubrication. Tribol. Lett. 52, 47-55. doi: 10.1007/s11249-013-0 191-1 
Zeng, Q., and Dong, G. (2014). Superlubricity behaviors of Nitinol 60 alloy under oil lubrication. Trans. Nonferrous Met. Soc. China 24, 354-359. doi: 10.1016/S1003-6326(14)63068-5

Zeng, Q., Dong, G., and Martin, J. M. (2016). Green superlubricity of Nitinol 60 alloy against steel in presence of castor oil. Sci. Rep. 6:29992. doi: 10.1038/srep29992

Zeng, Q., Zhao, X., Dong, G., and Wu, H. (2012). Lubrication properties of Nitinol 60 alloy used as high-speed rolling bearing and numerical simulation of flow pattern of oil-air lubrication. Trans. Nonferrous Met. Soc. China. 22, 2431-2438. doi: 10.1016/S1003-6326(11)61 481-7
Conflict of Interest Statement: The authors declare that the research was conducted in the absence of any commercial or financial relationships that could be construed as a potential conflict of interest.

Copyright (c) 2019 Vellore, Walters and Martini. This is an open-access article distributed under the terms of the Creative Commons Attribution License (CC BY). The use, distribution or reproduction in other forums is permitted, provided the original author(s) and the copyright owner(s) are credited and that the original publication in this journal is cited, in accordance with accepted academic practice. No use, distribution or reproduction is permitted which does not comply with these terms. 